〔Med. Entomol. Zool. Vol. 61 No. 4 p. 375-382 2010]

\title{
Two new species of Goniophyto from Honshu, Japan (Diptera: Sarcophagidae)
}

\author{
Hiromu KuRAHASHI \\ Department of Medical Entomology, National Institute of Infectious Diseases, \\ Toyama 1-23-1, Shinjuku-ku, Tokyo 162-8640 Japan
}

(Received: 10 June 2010; Accepted: 6 August 2010)

\begin{abstract}
Two new species of flesh flies, Goniophyto kakinumai sp. nov. and $G$. ubeensis sp. nov. are described and keyed. Male genitalia and head profiles are illustrated for a practical identification.
\end{abstract}

Key words: Goniophyto, new species, flesh fly, Sarcophagidae, Japan

\section{INTRODUCTION}

Through the courtesy of Mr. Susumu Kakinuma, I had an opportunity to examine a number of his sarcophagid specimens collected in Ube City, Yamaguchi Pref., Honshu, Japan. Among them, I found several specimens of unknown species of the genus Goniophyto (Diptera: Sarcophagidae). After examined enough number of specimens, I was able to distinguish two new species among these specimens. One of them has very similar features showing affinity to the previously known species, Goniophyto shanghaiensis Deng, Chen \& Fan, 2007 and another to G. horii Kurahashi \& Suenaga, 1994. However, two new species differ from the previous ones in parafacials largely setulosed. Descriptions and illustrations of these new species are given hereinafter. The previous key to the four Japanese species (Kurahashi and Suenaga, 1994) is revised to include the new species.

Key to the species of Goniophyto from Japan

1. Parafacial largely setulose on entire length (Fig. 1); median marginal bristles $(m b)$ on tergite 3 weakly developed, the length less than $1 / 2$ of those on tergite 4 in 우...2

- Parafacial setulose on only limited area of upper part; median $m b$ on tergite 3 well developed, the length usually more than $1 / 2$ of those on tergite 4 in 우 $\ldots \ldots \ldots . .3$

2. Aedeagus with vesica well developed, rounded, and lobulated; postgonite (pp) with distinct pointed apex like claw; vein $\mathrm{R}_{1}$ usually yellowish brown $\ldots \ldots \ldots \ldots \ldots \ldots$

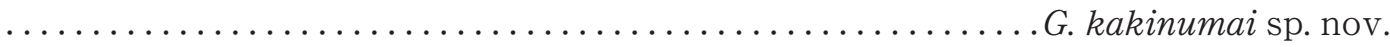

- Aedeagus with vesica less developed and triangular in shape; pp with truncate apex; vein $\mathrm{R}_{1}$ usually fuscous brown $\ldots \ldots \ldots \ldots \ldots \ldots \ldots \ldots \ldots \ldots \ldots$. ubeensis sp. nov.

3. Tibiae distinctly paler than femora and tarsi; mid tibia usually with 3 ad; sternopleuron largely covered with yellowish hairs on lower parts; lower parts of pteropleuron with yellowish hairs posteriorly; 3rd aristal segment slender on apical $1 / 2$ to $2 / 3$. . G. honshuensis Rohdendorf

- Legs including tibiae, black, sometimes entirely fuscous brown in teneral specimens; sternopleuron usually clothed with black hairs, sometimes intermixed with a few 

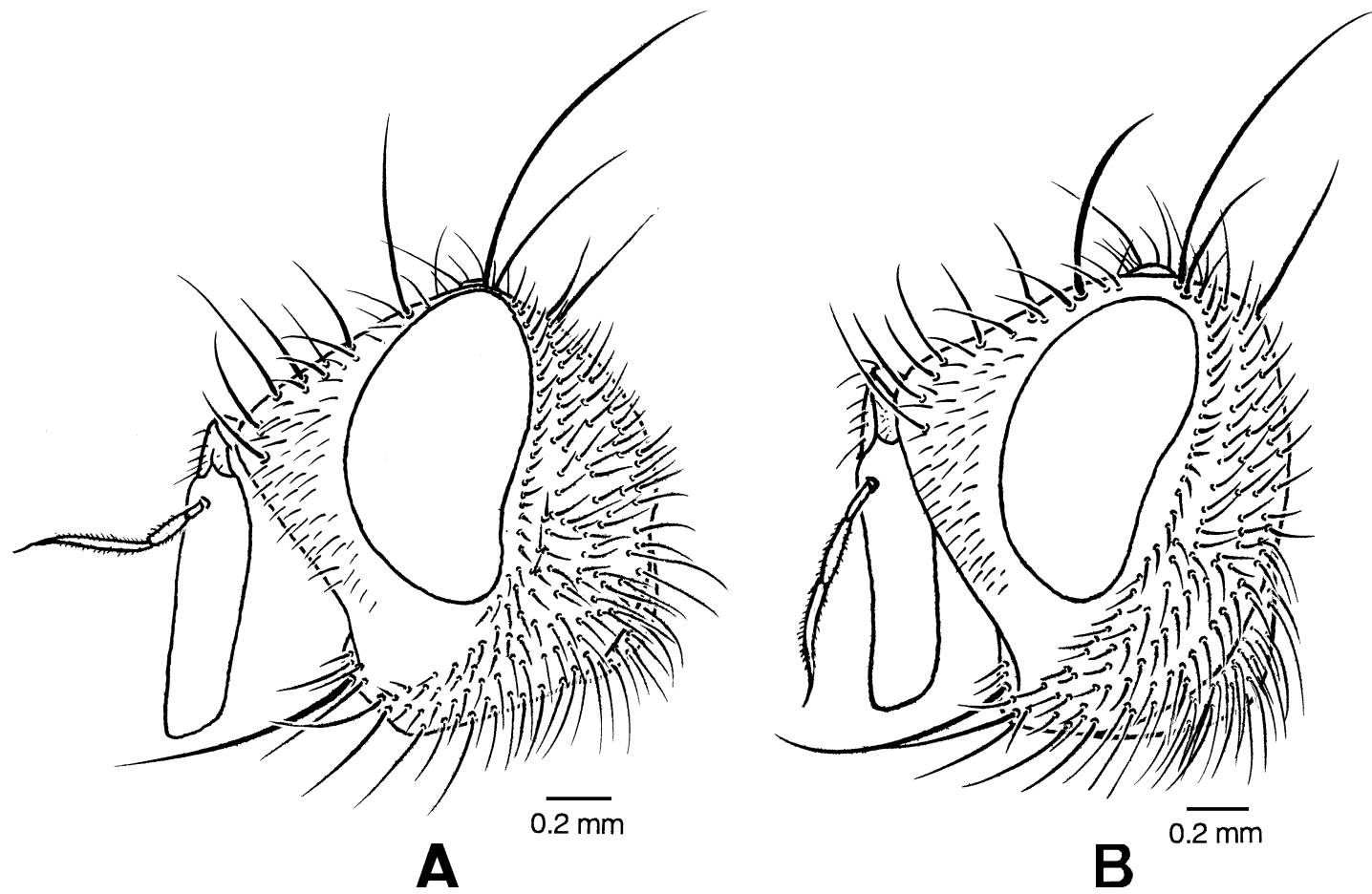

Fig. 1. Male head, lateral view.—A, Goniophyto kakinumai sp. nov.; B, G. ubeensis sp. nov.

yellowish brown ones, or the hairs becoming pale brown apically; lower parts of

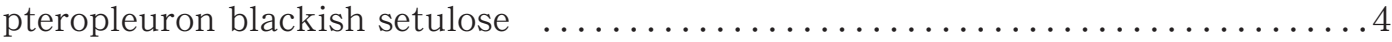

4. Frontal stripe blackish, more or less yellowish-grey dusted in front view, not sharply limited; median longitudinal stripe fuscous, not distinct on tergites 3 and 4; 3rd aristal segment slender on more than apical $1 / 2$; mid tibia with $2-3$ ad. Nansei Is. ..................................... yaeyamaensis Kano \& Shinonaga

- Frontal stripe submetallic black, sharply limited; median longitudinal stripe on tergites 3 and 4 blackish, distinct, coalesced at hind margin $\ldots \ldots \ldots \ldots \ldots$

5. Parafacial narrow, at narrowest point, less than width of ocellar triangle in $\sigma^{7}$ (cf Kurahashi and Suenaga, 1994: 228, Fig. 1b); tergite 6 with a pair of median $m b$ in $\sigma^{7}$; tergite $1+2$ usually with strong median $m b$; 3 rd aristal segment slender on more than apical 2/3; mid tibia with 2-3 ad. Ogasawara Is. ......... G. boninensis Lopes

- Parafacial broad, at narrowest point, more than width of ocellar triangle in $\sigma^{\top}$ (cf Kurahashi and Suenaga, 1994: 228, Fig. 1a); tergite 6 with two pairs of bristles in ot; tergite $1+2$ without median marginal bristle; 3rd aristal segment slender on less than apical 1/2; mid tibia usually with 2 ad. Kyushu and western parts of Honshu .G. horii Kurahashi \& Suenaga

\section{Goniophyto kakinumai sp. nov.}

(Japanese name: Kakinuma-hosonikubae)

DISCRIPTION. Male.- Head: dichoptic; eyes bare, widely separated at narrowest point by more than width of one eye; frons index $0.40-0.44(\mathrm{M}=0.44, \mathrm{n}=5)$; frontal stripe fuscous black, rather densely yellowish-grey dusted in front view, not sharply limited on lateral margins, broad, parallel-sided, slightly narrowed toward antennal base; parafro- 
ntal broad, densely brownish-grey dusted, with fine black setulae on entire length, provided with $c a$. 6 pairs of ori, upper most one strongest, directed outward, 3 proclinate ors weakly developed; parafacial narrower than width of $\mathrm{AS}_{3}$, but broader than width of ocellar triangle, at narrowest part, densely grey-dusted, more or less brown tinged above, largely clothed with black setulae on entire length; face black, densely silver-grey dusted, without facial carina; facialia black, densely silver-grey dusted, bare except for several black setulae just above vibrissae; mediana densely silver-grey dusted, bare; vibrissaria very narrow, black, silver-grey dusted, at most with several black setulae; vibrissa well developed; epistome brown, grey-dusted, not projecting forward in lateral view; gena narrow, less than width of $\mathrm{AS}_{3}$, black, grey-dusted, clothed with rather long black hairs; postgena concolorous with gena, clothed with black long hairs anteriorly except for several yellowish brown ones posteriorly; occiput concolorous with gena, clothed with black setulose hairs except for several yellowish ones on central portion; $\mathrm{AS}_{2}$ black, brownish-grey dusted, with black setulae; $\mathrm{AS}_{3}$ black, brownish-grey dusted, about 3.0 times as long as $\mathrm{AS}_{2}$; arista blackish, stout, pubescent except apical 1/5 of 3rd segment, 2nd segment long, longer than $1.5 \mathrm{x}$ as long as 1st; palpus entirely blackish, with black bristly hairs as well as ordinary black ones.

Thorax: black, grey-dusted, more or less brownish-tinged, clothed with black setulae; dorsum with single fuscous median and submedian vittae, lateral vitta broad, fuscous, but obscure on presutural area; humerus, notopleuron and sternopleuron concolorous with dorsum, densely grey-dusted, with black setulae, but several on anterior part of notopleuron; postalar callus and scutellum also concolorous with dorsum, with black setulae; prosternum bare; propleuron bare; supraspiracular convexity bare, greyish dusted; hypopleuron largely bare, but sometimes with a few black minute hairs along row of 4-5 hypopleural bristles; mesopleural, pteropleural and sternopleural hairs black; mesothoracic spiracle small, blackish with yellowish brown fringe; metathoracic spiracle small, blackish, posterior opercurum with yellowish brown fringe; postalar declivity bare; tympanic tuft absent; suprasquamal ridge without either anterior or posterior parasquamal tufts. Chaetotaxy: presutural row of $a c$ more or less developed, distinct from ground hairs, prescutellar $a c$ fine; $d c 2+3$ strongly developed; $i a 0+2 ; h 2-4,2$ of them usually developed; $p h$ 1-2; prs 1 ; sa 3 ; pa 2 ; st $1+1$; sc $2+1$, discal one very fine; $n 2$; $p$ p $1-2$; $p s t 1-$ $2, p p$ and pst accompanying with a few bristly hairs.

Wings: hyaline; veins fuscous brown; epaulet brown, silver pubescence basally; basicosta yellowish white, with silver pubescence; subcostal sclerite yellowish white, with silver pubescence; first longitudinal vein $\left(\mathrm{R}_{1}\right)$ bare; costal spine developed; node of 2nd $\left(\mathrm{R}_{2+3}\right)$ and 3rd longitudinal veins with a few black setulae below; 3rd longitudinal vein $\left(\mathrm{R}_{4+5}\right)$ with about 7 black setulae from node of 2 nd and 3 rd veins to anterior cross vein $(\mathrm{r}-\mathrm{m})$; 4 th longitudinal vein $\left(\mathrm{M}_{1+2}\right)$ bent with right angle, with trace of stalk; section of 4 th bend to wing edge gently curved inward near bend. Alar and thoracic squamae pale brown, thoracic one lobulate, bare, with more or less fuscous margin. Halteres pale brown.

Legs: black, dark-grey dusted, black haired; fore tibia with $1 p, 1 p d$ and 3 ad; mid tibia with $2 a d, 2 p d$ and $1 v$; hind tibia with $2-3 a d, 2 p d$ and $1 a v$.

Abdomen: black, grey-dusted, especially on anterior parts of tergites; tergite $1+2$ grey-dusted laterally; tergites 3-4 with 3 (1 median black and 2 lateral triangular dark) spots which coalesce at hind margin; tergite $1+2$ with 1 strong lateral $m b$; tergite 3 with a pair of strong median $m b$, single lateral $m b$ also developed; tergite 4 with a pair of strong median $m b$, two strong lateral $m b$ also developed; tergite 5 with row of strong $m b$; sternites black, dark-grey dusted; sternite 1 and anterior part of sternite 2 black haired. Hypopygium prominent; tergite 6 combined with genital segments, submetallic, with 4 


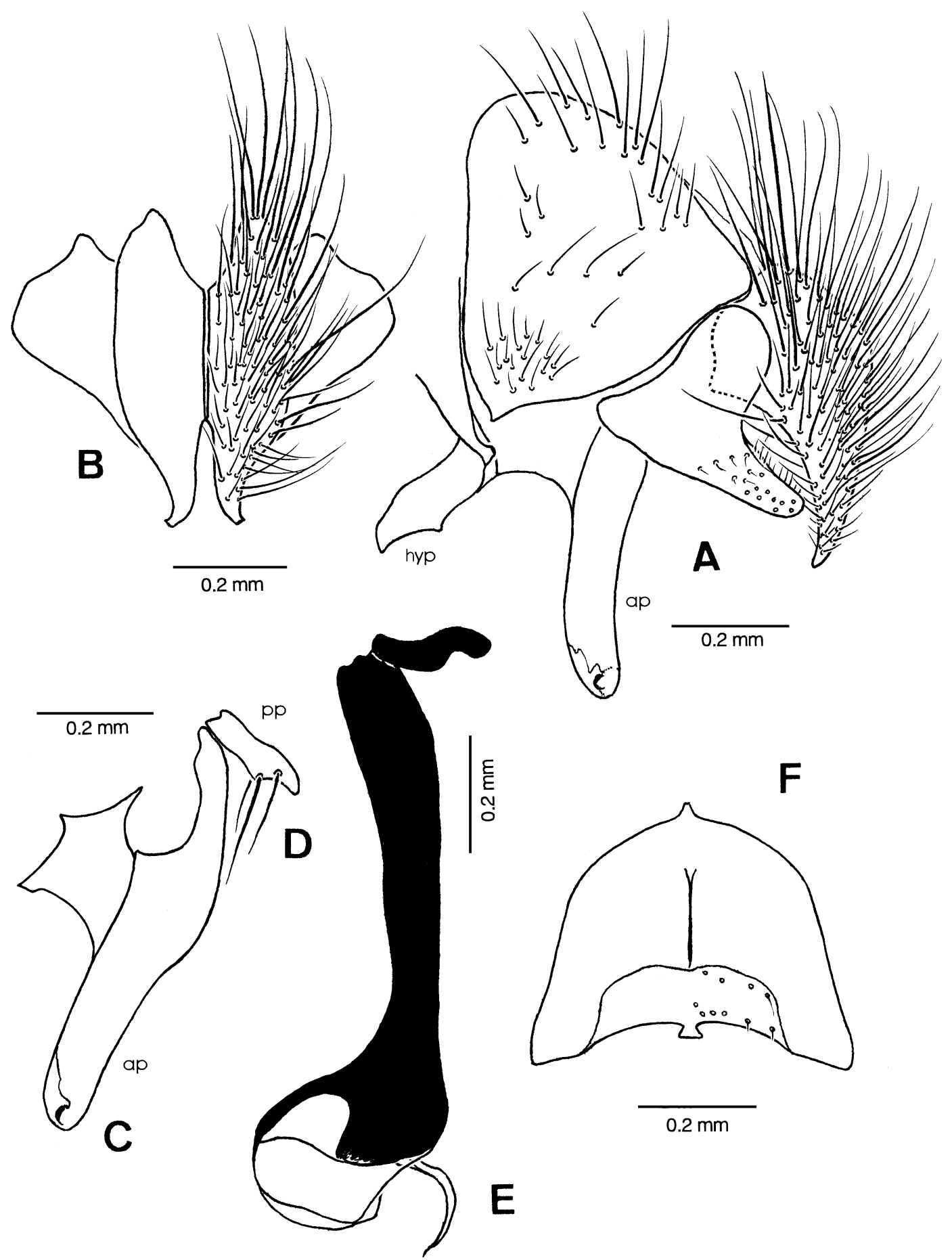

Fig. 2. Goniophyto kakinumai sp. nov., male genitalia.—-A, epandrium, cercus, surstylus, hypandrium (hyp) and pregonite (ap), lateral view; B, cerci and surstyli, caudal view; C, pregonite (ap), lateral view; D, postgonite (pp), lateral view; E, aedeagus, lateral view; F, sternite 5, ventral view. 
fine $m b$; genital segment $1\left(\mathrm{GS}_{1}\right)$ and genital segment $2\left(\mathrm{GS}_{2}\right)$ or epandrium submetallic, less dark-grey dusted; $\mathrm{GS}_{1}$ with a pair of rather strong $m b$. Male genitalia as shown in Fig. $2 \mathrm{~A}-\mathrm{E}$.

Female- - Head: eyes bare, widely separated at vertex by more than width of one eye; frons index $0.45(n=1)$; frontal stripe broad, parallel-sided, slightly narrowed above level of strong proclinate ors, brownish-grey dusted, broader than width of parafrontal at level of anterior ocellus; parafrontal broad, broader than width of frontal stripe at level of lower strong proclinate ors, grey-dusted, brownish tinged posteriorly, provided with 6 pairs of strong ori; ors $2+0$; oc weakly developed; acoc fine; pooc weakly developed; $i v$ strongly developed; ov less developed, length subequal to $1 / 2$ that of $i v$; poc parallel; occ 1 , strongly developed.

Abdomen: more robust than that of male. Ovipositor short. Otherwise same as for $\sigma^{7}$. Length. 4.8-7.5 mm.

Holotype ऽ7, HONSHU: Yamaguchi Pref., Ube City, Okinodan, Koto River, 4.iii. 2009, S. Kakinuma, NSMT-I-Dip6733.

Paratypes. HONSHU: 3ð 1우, same locality as for holotype, 3.iv. 2008, 13.iv. 2009, 28.iv. 2009; 1万', Yamaguchi Pref., Ube City, Okinodan, 0 m, river side, 8.iii. 2010, H. Kurahashi.

Type depository. Holotype and paratypes ( $1 \sigma^{7} 1$ 우) are deposited in the National Museum of Nature and Science, Tokyo (NSMT). 10 $\sigma^{7}$, Bishop Museum, Honolulu (BPBM); $1 \sigma^{\top}$, Natural History Museum, London (BMNH); 1 $\sigma^{\top}$, Zoological Museum University of Copenhagen (ZMUC).

Etymology. The specific epithet is named in honour of Mr. Susumu Kakinuma who is a local entomologist and first discovered this interesting new species.

Relationships. The present new species is closely allied to Goniophyto shanghaiensis Deng, Chen \& Fan, 2007 in the general morphology of male genitalia, but it is easily distinguished by the parafacials entirely setulose and the black coloration of tibiae. Goniophyto kakinumai sp. nov. is also similar to G. horii Kurahashi \& Suenaga, 1994, but it can be easily differentiated by the parafacials entirely setulosed, the first sternite clothed with black hairs and no reclinate ors developed in 우.

Bionomics. Adults are found in the marshes near the river mouth flowing into the inner sea of Setonaikai, Japan.

Distribution. Palaearctic Region: Japan (Honshu).

Goniophyto ubeensis sp. nov.

(Japanese name: Ube-hosonikubae)

DISCRIPTION. Male.- Head: dichoptic; eyes bare, widely separated at narrowest point by more than width of one eye; frons index $0.43-0.46(\mathrm{M}=0.44, \mathrm{n}=20)$; frontal stripe fuscous black, rather densely yellowish-grey dusted in front view, not sharply limited on lateral margins, broad, parallel-sided; parafrontal broad, brownish-grey dusted, with fine black setulae on entire length, provided with $c a$. 6 pairs of ori, upper most one strong, directed outward, 2-3 proclinate ors weakly developed; parafacial narrower than width of $\mathrm{AS}_{3}$, but broader than width of ocellar triangle, at narrowest part, grey-dusted, more or less brown tinged above, entirely blackish setulosed; face black, densely silvergrey dusted, without facial carina; facialia black, densely silver-grey dusted, bare except for several black setulae just above vibrissa; mediana densely silver-grey dusted, bare; vibrissaria very narrow, black, silver-grey dusted, at most with several black setulae; vibrissa well developed; epistome brown, grey-dusted, not projecting forward in lateral view; gena narrow, less than width of $\mathrm{AS}_{3}$, black, grey-dusted, clothed with rather long black hairs; postgena concolorous with gena, clothed with black long hairs anteriorly 

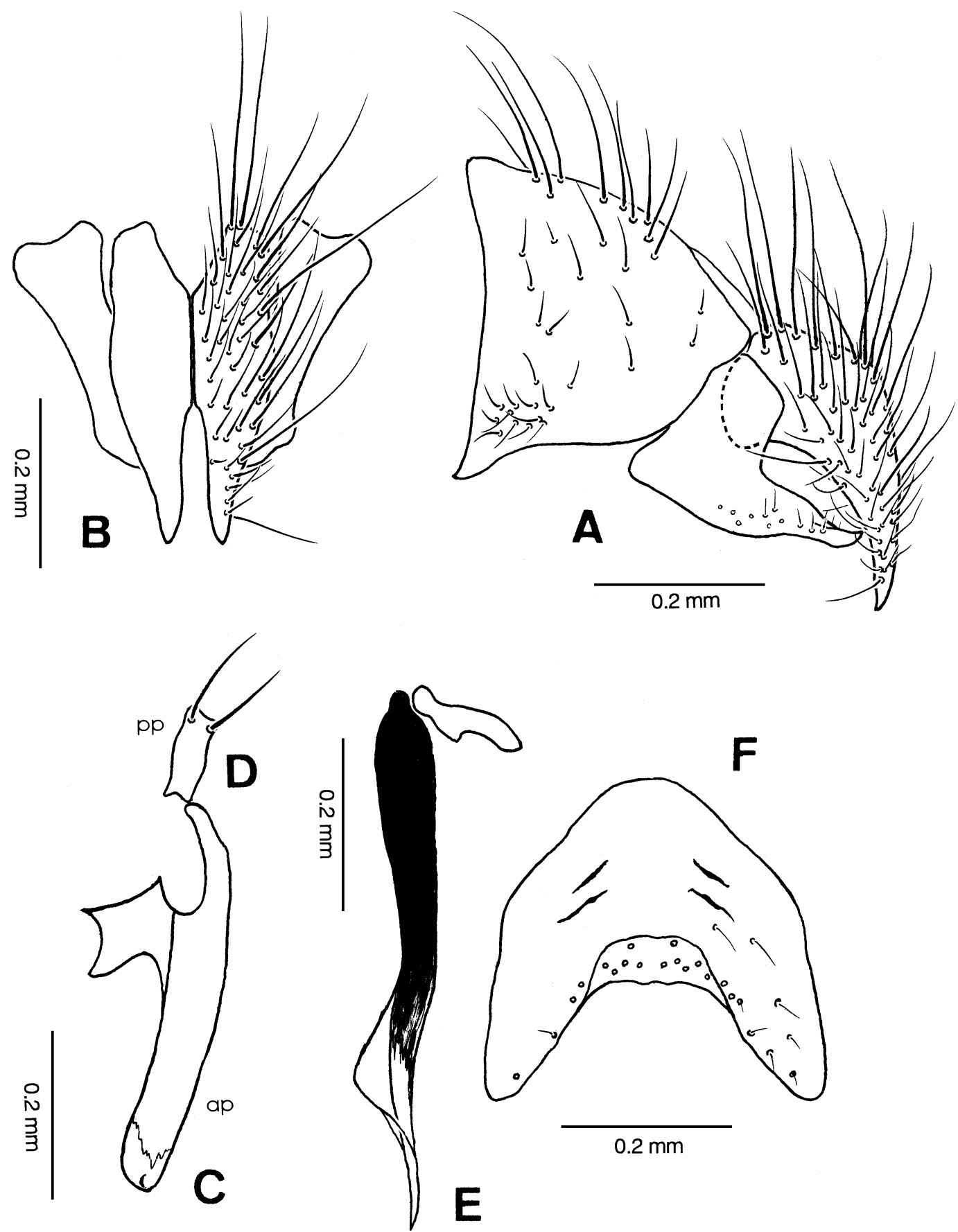

Fig. 3. Goniophyto ubeensis sp. nov., male genitalia.—A, epandrium, surstylus and cercus, lateral view; B, cerci and surstyli, caudal view; C, pregonite (ap), lateral view; D, postgonite (pp), lateral view; E, aedeagus, lateral view; F, sternite 5 , ventral view. 
except for several yellowish brown ones posteriorly; occiput concolorous with gena, clothed with black setulose hairs except for a few yellowish ones on central portion; $\mathrm{AS}_{2}$ black, brownish-grey dusted, with black setulae; $\mathrm{AS}_{3}$ black, slightly brownish-grey dusted, about 3.0 times as long as AS2; arista blackish, stout, pubescent except apical 1/ 5 of 3 rd segment, 2nd segment long, longer than $1.5 \mathrm{x}$ as long as 1st; palpus entirely blackish, with black bristly hairs as well as ordinary black ones.

Thorax: black, grey-dusted, more or less brownish-tinged, clothed with black setulae; dorsum with single fuscous median and submedian vittae; lateral vitta broad, fuscous, but obscure on presutural area; humerus, notopleuron and sternopleuron concolorous with dorsum, densely grey-dusted, with black setulae, but several on anterior part of notopleuron; postalar callus and scutellum also concolorous with dorsum, with black setulae; prosternum bare; propleuron bare; supraspiracular convexity bare, greyish dusted; hypopleuron largely bare except for a few black minute hairs around row of 4-5 hypopleural bristles; mesopleural, pteropleural and sternopleural hairs black; mesothoracic spiracle small, blackish with yellowish brown fringe; metathoracic spiracle small, blackish, posterior opercurum with yellowish brown fringe; postalar declivity bare; tympanic tuft absent; suprasquamal ridge without either anterior or posterior parasquamal tufts. Chaetotaxy: presutural row of $a c$ not so much developed, but distinct from ground hairs, prescutellar $a c$ absent or weakly developed; $d c 2+3$ strongly developed; $i a$ $0+2 ; h 2-4,2$ of them usually developed; ph 1 ; prs $1 ; s a 2,1$ fine additionals present between strong 2; pa 2; st $1+1$; sc $2+1$, discal one very fine; $n 2$; pp 1 ; pst 1 , pp and $p s t$ accompanying with a few bristly hairs.

Wings: hyaline; veins fuscous brown; epaulet brown, silver pubescence basally; basicosta yellowish white, with silver pubescence; subcostal sclerite yellowish white, with silver pubescence; vein $\mathrm{R}_{1}$ bare; costal spine developed; node of veins $\mathrm{R}_{2+3}$ and $\mathrm{R}_{4+5}$ with a few black setulae below; vein $R_{4+5}$ with about 7 black setulae from node of veins $\mathrm{R}_{2+3}$ and $\mathrm{R}_{4+5}$ to $\mathrm{r}-\mathrm{m}$; vein $\mathrm{M}_{1+2}$ bent with right angle, with trace of stalk; section of $\mathrm{M}_{1+2}$ bend to wing edge gently curved inward near bend. Alar and thoracic squamae pale brown, thoracic one lobulate, bare, with more or less fuscous margin. Halteres pale brown.

Legs: black, dark-grey dusted, black haired; fore tibia with $1 p, 1 p d$ and $3 a d$; mid tibia with 2-3 ad, $2 p d$ and $1 v$; hind tibia with 2-3 ad, $2 p d$ and $1 a v$.

Abdomen: black, grey-dusted, especially on anterior parts of tergites; tergite $1+2$ grey-dusted laterally; tergites 3-4 with 3 (1 median black and 2 lateral triangular dark) spots which coalesce at hind margin; tergite $1+2$ with 1 strong lateral $m b$; tergite 3 with a pair of strong median $m b$, single lateral $m b$ also developed; tergite 4 with a pair of strong median $m b$, two strong lateral $m b$ also developed; tergite 5 with row of strong $m b$; sternites black, dark-grey dusted; sternite 1 and anterior part of sternite 2 fuscous black haired. Hypopygium prominent; tergite 6 combined with genital segments, submetallic, with 2-4 fine $m b$; $\mathrm{GS}_{1}$ and $\mathrm{GS}_{2}$ or epandrium submetallic, more or less dark-grey dusted; $\mathrm{GS}_{1}$ with a pair of rather strong $m b ; \mathrm{GS}_{2}$ with $1-2 m b$. Male genitalia as shown in Fig. 3 A-E.

Female. unknown.

Length. 5.5-7.5 mm.

Holotype ơ , HONSHU: Yamaguchi Pref., Ube City, Okinodan, Koto River, 21.ii. 2010, S. Kakinuma, NSMT-I-Dip6734.

Paratypes. HONSHU: $3 \sigma^{7}$, same data as holotype; $7 \sigma^{7}$, same locality as holotype, 14 .iv.

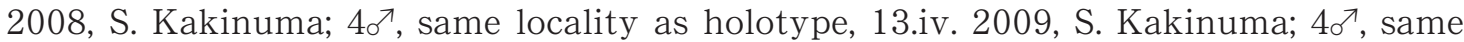
locality as holotype, 3.iv. 2008, S. Kakinuma; 3ð , same locality as holotype, 4.iii. 2009, S. Kakinuma; $1 \sigma^{\text {T}}$, same locality as holotype, 24.v. 2007, S. Kakinuma; $\sigma^{\top}$, same locality as holotype, 6.iv. 2009, S. Kakinuma; 4ð', Yamaguchi Pref., Ube City, Okinodan, 0 m, river 
side, 8.iii. 2010, H. Kurahashi.

Type depository. Holotype and paratypes $\left(20 \sigma^{\top}\right)$ are deposited in the National Museum of Nature and Science, Tokyo (NSMT). 20 ${ }^{\top}$, Bishop Museum, Honolulu (BPBM); $20^{\top}$, Natural History Museum, London (BMNH); $2 \sigma^{\top}$, Zoological Museum University of Copenhagen (ZMUC); $2 \sigma^{7}$, Carnegie Museum of Natural History, Pittsburgh (CMNH).

Etymology. The specific epithet is named after the type locality "Ube City".

Relationships. The present new species is closely allied to Goniophyto horii Kurahashi \& Suenaga, 1994 in the general morphology of male genitalia, but it is easily distinguished by the parafacials entirely clothed with blackish setulae. Goniophyto ubeensis sp. nov. is very similar to G. kakinumai sp. nov., and it can be hardly identified without examining the male genitalia.

Bionomics. Adults are found in the marshes near the river mouth flowing into the inner sea of Setonaikai, Japan.

Distribution. Palaearctic Region: Japan (Honshu).

\section{ACKNOWLEDGEMENTS}

The present author wishes to express his sincere thanks to Mr. S. Kakinuma, a local entomologist studying dipteran insects in Yamaguchi City for providing the valuable material for description.

\section{REFERENCES}

Deng, Y., Chen, Z. and Fan, Z. 2007. A new species of Goniophyto (Diptera: Sarcophagidae) from China with a key to species and diagnosis of the genus. Entomotaxonomia, 29: 137-142.

Kurahashi, H. and Suenaga, O. 1994. A new species of Goniophyto from Kyushu, Japan (Diptera; Sarcophagidae). Jpn. J. Sanit. Zool., 45: 227-231. 